\title{
Mechanism of Viscous Flow in Silicate Melt*
}

\section{By Osamu HAIDA ${ }^{* *}$ and Toshihiko Emi**}

\begin{abstract}
Synopsis
Recent development in the theories of viscous flow in silicate melts is critically reviewed, with brief survey on the structure of the melts. Factors to be involved in a satisfactory modelistic theory are discussed, referring to existing $n$ odels. Importance is stressed of cooperative nature of motion of flow species for viscous flow to occur in silicate melts.
\end{abstract}

\section{Introduction}

Recent review $^{1)}$ has indicated that the rate of many slag/metal reactions in metallurgical systems are controlled predominantly by mass transfer processes involved. Since the rate of mass transfer is usually slower in slag melts even with stirring, control of slag viscosity is of much practical importance to enhance the reactions in refining metals. Also, the viscosity of slag melts has been shown ${ }^{2)}$ to be one of factors determining surface quality of slabs and ingots cast under slags.

In contrast to abundant data and means available for controlling the viscosity, our understanding on the mechanism of viscous flow has been limited because of complicated structure of slag melts. However, recent advance in the knowledge on the ionic and polymeric constitution of the melts, combined with extensive investigation into the mechanism of viscous flow, are going to make it possible to reveal exact nature of viscous flow.

This article is intended to give present status of development in the mechanism of viscous flow with special reference to the structure of silicate melts.

\section{Ionic Structure of Slag Melts}

Random network model worked out by Zacharia$\operatorname{sen}^{3)}$ and Warren ${ }^{4)}$ from X-ray diffraction analysis of amorphous silicates, and discrete anion model proposed by Bockris and his colleagues ${ }^{5-7)}$ on the basis of physical and kinetic properties of silicate melts, have long been two major pictures for the structure of silicate slag melts. Recently, marked advance in the modelistic theories of ionic structure of the slag melts has made it possible to explain thermodynamic quantities in terms of ionic species of the melts.

The activity, $a$, of metal oxide, MO, in ionic melts was given by Temkin ${ }^{1)}$ as

$$
a_{\mathrm{MO}}=a_{\mathrm{M}^{2+}} \cdot a_{\mathrm{O}^{2-}}=\mathcal{N}_{\mathrm{M}^{2+}} \cdot \mathcal{N}_{\mathrm{O}^{2-}}
$$

where $\mathcal{N}$ 's are cationic and anionic fractions. Equation (1) is obviously only approximate for multicomponent silicate melts, because ionic strength varies with wide variety of composition of the melts, supporting electrolyte is not existing in the melts, and hence equality of the 2nd to 3rd terms in Eq. (1) is somewhat questionable. Nevertheless, this approximation has found extensive use in the following treatments.

In binary silicate melts, $\mathrm{MO}-\mathrm{SiO}_{2}$, one has

$$
\mathrm{MO}=\mathrm{M}^{2+}+\mathrm{O}^{2-}
$$

and

$$
\mathrm{O}^{2-}+\left(\rightarrow \mathrm{Si}-\mathrm{O}-\mathrm{Si}\langle)=2\left(\rightarrow \mathrm{Si}-\mathrm{O}^{-}\right)\right.
$$

or alternatively

$$
\mathrm{O}^{2-}+\mathrm{O}^{0}=2 \mathrm{O}^{-}
$$

It is customaly to take only $\mathrm{M}^{2+}$ as cationic species and the rest, such as $\mathrm{O}^{2-}, \mathrm{SiO}_{4}^{4-}, \mathrm{Si}_{2} \mathrm{O}_{7}^{6-}$, and so forth, as anionic species. Then, $a_{\mathrm{M}^{2+}}$, or $\mathcal{N}_{\mathrm{M}^{2+}}$, is unity and hence $a_{\mathrm{Mo}}$ becomes equal to $\mathcal{N}_{\mathrm{O}^{2-}}$ in Eq. (1).

Here, the concept of activities of MO molecules and of charged oxygen seems unreasonable in view of the fact that the molecules are not existing in the melts and $a_{0^{2-}}$ cannot experimentally be determined. However, $a_{\mathrm{MO}}$ and $a_{\mathrm{O}^{2-}}$ are convenient measures to deal respectively with slag formation reactions and with metallurgically important slag/metal reactions in which $\mathrm{O}^{2-}$ 's are involved. Derivation of these activities has, therefore, been one of the principal objects of the modelistic theories which can be divided into two categories.

The first approach is to avoid complications arising from explicit evaluation of the distribution of complex silicate anions, and to deal formally with equilibrium between oxygen ions $\left(\mathrm{O}^{2-}\right)$, doubly bonded oxygen atoms $\left(\mathrm{Si}-\mathrm{O}-\mathrm{Si}\right.$ as $\mathrm{O}^{0}$ ), and singly bonded oxygen atoms $\left(\mathrm{Si}-\mathrm{O}^{-}\right.$as $\left.\mathrm{O}^{-}\right)$: this was first attempted by Toop and Samis ${ }^{91}$, then by Kapoor and Frohberg. ${ }^{10)}$ The activities of the components of binary silicate melts $\left(a_{\mathrm{MO}}\right.$ and $a_{\mathrm{SiO}_{2}}$ ) and the free evergy change of formation of the binary silicate melts $(\Delta G)$ were related in these theories to an equilibrium constant, $K=$ $\left[\mathrm{O}^{2-}\right]\left[\mathrm{O}^{0}\right] /\left[\mathrm{O}^{-}\right]^{2}$, and to the mole fraction, $X$, of $\mathrm{SiO}_{2}$, by taking into account charge and mass balance of oxygen- and silicon-ions. The values of $K$ were chosen to give best fit of calculated to observed values of $\Delta G\left(\right.$ or $a_{\mathrm{MO}}$ and $\left.a_{\mathrm{SiO}_{2}}\right)$, then $\left[\mathrm{O}^{2-}\right],\left[\mathrm{O}^{0}\right]$, and $\left[\mathrm{O}^{-}\right]$ were obtained subsequently as a function of $X_{\mathrm{SiO}_{2}}$.

One more interesting contribution along this line of approach was made by Yokokawa and Niwa ${ }^{11)}$ on the basis of a random network model. A quasi-lattice treatment was employed to evaluate partition function of silicate melts on the assumption that a melt containing $n$ and $m$ molecules of $\mathrm{MO}$ and $\mathrm{SiO}_{2}$ is a

* Received September 5, 1974.

** Research Laboratories, Kawasaki Steel Corp., Kawasaki-cho 1, Chiba 280. 


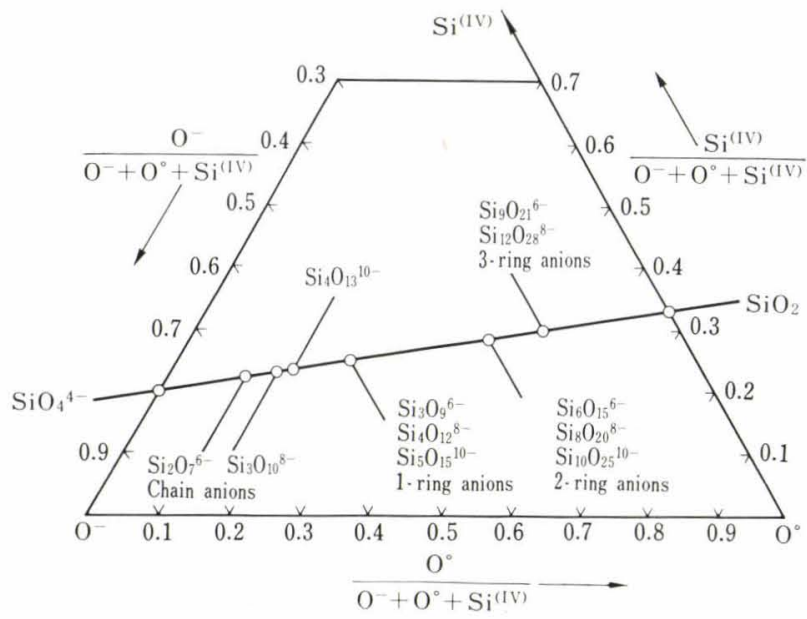

Fig. 1. Ternary plot of the proportions of singly bonded oxygen, silicon and doubly bonded oxygen in any discrete silicate anion ${ }^{9)}$

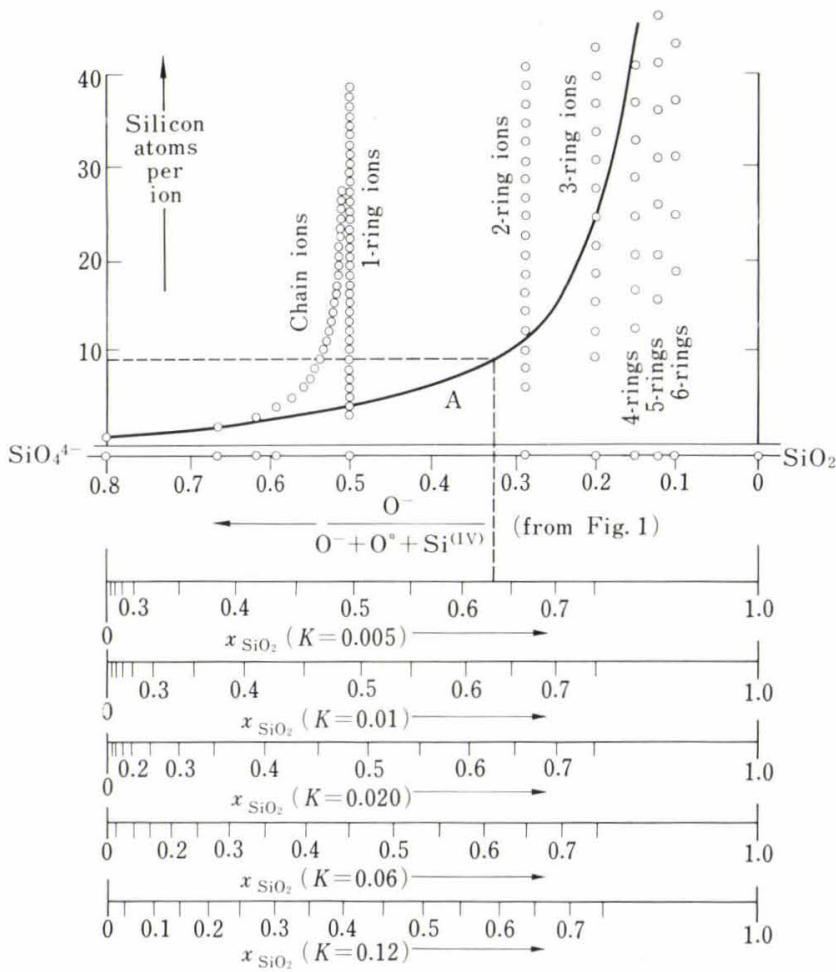

Fig. 2. Plot of the proportion of singly bonded oxygen atoms in the most probable or mean silicate anions present vs. the number of silicon atoms per ion for various values of $X_{\mathrm{SiO}_{2}}$ and $K^{91}$

matrix consisting of $(n+2 m)$ oxygen and sites for $\mathrm{M}$ and Si. The number of sites for Si is $\left(m+\frac{1}{2} n\right)$ only $m$ of which are occupied. An oxygen atom was considered to face two vacant sites which are available for Si. Occupancy of 0,1 , or 2 vacant sites by $\mathrm{Si}$ corresponds to $\mathrm{O}^{2-}, \mathrm{O}^{-}$, or $\mathrm{O}^{0}$. After $\mathrm{Si}$ atoms were distributed among the vacant sites, positions of $\mathrm{M}^{2+}$ ions were automatically and uniquely determined depending on the geometrical and charge distributional factors. Here, the energy of modification or the energy of $\mathrm{O}^{-}$relative to $\mathrm{O}^{2-}$ and $\mathrm{O}^{0}$ is assumed constant $\left(E_{w}\right)$, regardless of the composition of the melts. This means that the the enthalpy change of Eqs. (2) and (3) is equal to $2 E_{w}$ (cal/bond). The partition func-

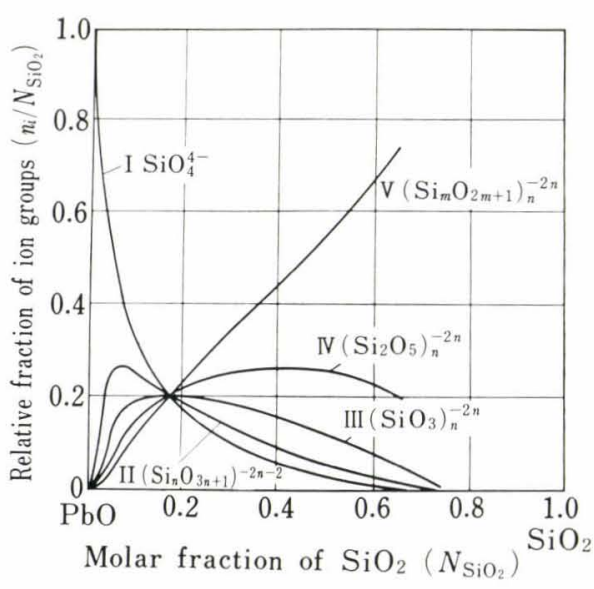

Fig. 3. Fraction of ion groups vs. composition curves calculated for $\mathrm{PbO}-\mathrm{SiO}_{2}$ melts at $1100^{\circ} \mathrm{C}(K=1)^{10}$ )

tion thus evaluated yielded the values of $\Delta G, a_{\mathrm{MO}}$, and $a_{\mathrm{SiO}_{2}}$. An advantage of the Yokokawa-Niwa model is that it could get rid of the Temkin equation which was introduced as an inevitable assumption in the Toop-Samis and Kapoor-Frohberg model.

Regarding the distribution of silicate anions, Toop and Samis ${ }^{9)}$ considered conceivable silicate anions, and gave graphical illustration of the proportions of tetrahedrally coordinated silicon, $\mathrm{Si}^{(\mathrm{IV})}, \mathrm{O}^{-}$, and $\mathrm{O}^{0}$ in any discrete silicate anion as shown in Fig. 1. This, combined with Fig. 2, served to estimate the distribution in the melts. In Fig. 2, 1 mole of MO$\mathrm{SiO}_{2}$ type melt (e.g., $\left.K=0.005\right)$ containing 0.63 moles of $\mathrm{SiO}_{2}$ has anions in which average number of $\mathrm{Si}$ atoms is, as shown by dotted lines, about 9 . Accordingly, anions existing would probably consist of double-ring anions containing 8 to $10 \mathrm{Si}$ atoms/ion, i.e., $\mathrm{Si}_{8} \mathrm{O}_{20}^{8-}$ or $\mathrm{Si}_{10} \mathrm{O}_{25}^{10-}$ with some single ring anions, possibly $\mathrm{Si}_{3} \mathrm{O}_{9}^{6-}$ or $\mathrm{Si}_{5} \mathrm{O}_{15}^{10-}$, and some triple-ring aniions, i.e., $\mathrm{Si}_{12} \mathrm{O}_{28}^{8-}$ to $\mathrm{Si}_{15} \mathrm{O}_{35}^{10-}$. The most probable number of these silicate anions present would be $0.07=(0.63 / 9) \mathrm{mole} / \mathrm{mole}$ of melt.

Kapoor and Frohberg ${ }^{10}$ noticed that only the following configurations of $\mathrm{O}^{-}$and $\mathrm{O}^{0}$ are possible around a $\mathrm{Si}$ atom, i.e., $\mathrm{SiO}_{4}^{4-}, \mathrm{SiO}^{0} \mathrm{O}_{3}^{3-}, \mathrm{SiO}_{2}^{0} \mathrm{O}_{2}^{2-}$, $\mathrm{SiO}_{3}^{0} \mathrm{O}^{-}$, and $\mathrm{SiO}_{4}^{0}$, or more generally, $\mathrm{SiO}_{4}^{4-},\left(\mathrm{Si}_{n}\right.$ $\left.\mathrm{O}_{3^{n+1}}\right)^{-2 n-2},\left(\mathrm{SiO}_{3}\right)_{n}^{-2 n},\left(\mathrm{Si}_{2} \mathrm{O}_{5}\right)_{n}^{-2 n}$, and $\left(\mathrm{Si}_{m} \mathrm{O}_{2 m+1}\right)_{n}^{-2 n}$. Calculating the most probable distribution of the five configurations gave the distribution of complex silicate anions as a function of $X_{\mathrm{SiO}_{2}}$. The result for $\mathrm{PbO}-$ $\mathrm{SiO}_{2}$ melts is shown in Fig. 3.

The second approach, contrary to the foregoing models, deals explicitly with the distribution of discrete anions. Main contribution along this approach has been due to Masson and his colleagues. ${ }^{12-15)}$ It was assumed that self condensation of chains to yield ring structures or networks does not occur and that all $\mathrm{O}^{-}$groups are chemically equivalent regardless of the size of the anions to which they are attached. Application of polymer theory to the following polycondensation reaction

$$
\mathrm{SiO}_{4}^{4-}+\mathrm{Si}_{n} \mathrm{O}_{3 n+1}^{2(n+1)-} \rightleftarrows \mathrm{Si}_{n+1} \mathrm{O}_{3 n+4}^{2(n+2)-}+\mathrm{O}^{2-} .
$$

was attempted firstly by considering that the equili- 
brium constants for reaction (4) are the same and independent of chain length, i.e., monomeric $\mathrm{SiO}_{4}^{4-}$ 's are bifunctional ${ }^{12)}$ :

$$
\begin{aligned}
K=K_{11} & =\frac{\mathcal{N}_{\mathrm{Si}_{2} \mathrm{O}_{7}} \cdot \mathcal{N}_{\mathrm{O}^{2-}}}{\left(\mathcal{N}_{\mathrm{SiO}_{4}}\right)^{2}}=\ldots \ldots \\
& =k_{1 n}=\frac{\mathcal{N}_{\mathrm{Si}_{n+1} \mathrm{O}_{3 n+4}} \cdot \mathcal{N}_{\mathrm{O}^{-2}}}{\mathcal{N}_{\mathrm{SiO}_{4}} \cdot \mathcal{N}_{\mathrm{Si}_{n} \mathrm{O}_{3 n+1}}}
\end{aligned}
$$

Change of $a_{\mathrm{MO}}$ with $X_{\mathrm{SiO}_{2}}$, and molecular weight distributions of silicate polyions for this linear chain model were calculated with the help of the Temkin equation to be

$$
\begin{aligned}
1 / X_{\mathrm{SiO}_{2}}= & 2+\frac{1}{1-a_{\mathrm{MO}}}-\frac{1}{1+a_{\mathrm{MO}}\left(\frac{1}{k}-1\right)} \\
\mathcal{N}_{\mathrm{Si}_{n} \mathrm{O}_{3 n+1}=} & \left\{1+\frac{a_{\mathrm{MO}}}{k_{11}\left(1-a_{\mathrm{MO}}\right)}\right\}^{1-n} \\
& \times\left\{\left(k_{11} / a_{\mathrm{MO}}\right)+\frac{1}{1-a_{\mathrm{MO}}}\right\}^{-1} \ldots \ldots . .
\end{aligned}
$$

For multinfunctional condensation, however, equal reactivity of functional groups as expressed in Eq. (5) for the bifunctional linear chain model fails, because the number of sites available for growth and degradation by reaction (4) varies with $n$. Calculating the variation of $k_{1^{n}}$ with $n$ is equivalent to calculating the configurational aspect of the molecular size distribution in polyfunctional condensations. For tetrafunctional condensation of monomeric $\mathrm{SiO}_{4}^{4-}$, Masson and his associates gave ${ }^{14)}$

$$
1 / X_{\mathrm{SiO}_{2}}=2+\frac{1}{1-a_{\mathrm{MO}}}-\frac{1}{1+a_{\mathrm{MO}}\left(\frac{3}{k_{11}}-1\right)}
$$

and

$$
\begin{aligned}
& \mathcal{N}_{\mathrm{Si}_{n} \mathrm{O}_{3 n+1}}=\frac{(3 n) !}{(2 n+1) ! n !}\left(1-a_{\mathrm{MO}}\right) \\
& \times\left\{1+\frac{3 a_{\mathrm{MO}}}{k_{11}\left(1-a_{\mathrm{MO}}\right)}\right\}^{1-n}\left\{1+\frac{k_{11}\left(1-a_{\mathrm{MO}}\right)}{3 a_{\mathrm{MO}}}\right\}^{-(2 n+1)}
\end{aligned}
$$

when intramolecular condensation is neglected. Since all chain configurations were allowed, this may be called all chain configuration model.

Comparison of experimental data with Eqs. (6) and (8) indicated that $a_{\mathrm{MO}}$ for $\mathrm{CoO}-\mathrm{SiO}_{2}(k=2.0)$ could be represented by Eq. (6), the linear chain model, whereas $a_{\mathrm{Mo}}$ for $\mathrm{SnO}-\mathrm{SiO}_{2} \quad\left(k_{11}=2.55\right), \mathrm{FeO}-\mathrm{SiO}_{2}$ $\left(k_{11}=0.70\right), \mathrm{MnO}-\mathrm{SiO}_{2}\left(k_{11}=0.25\right)$, and $\mathrm{PbO}-\mathrm{SiO}_{2}$ $\left(k_{11}=0.196\right)$ could be interpreted in terms of Eq. (8), the all chain configuration model. For $\mathrm{CaO}-\mathrm{SiO}_{2}$ $\left(k_{11}=0.0016\right)$, it was not possible to distinguish experimentally between the theories. Assuming that $\mathrm{CaO}-\mathrm{SiO}_{2}$ undergoes all chain configurations, anion distribution was calculated which is shown in Fig. 4. The monomer, $\mathrm{SiO}_{4}^{4-}$, is the most abundant species of silicate ions at all compositions and almost the sole species below $x_{\mathrm{SiO}_{2}}=0.3$.

As pointed out by Masson ${ }^{14)}$, linear chain and all configuration models are valid below $x_{\mathrm{SiO}_{2}}=0.5$. It should be reminded, too, that the two models disregarded the possibility of self-condensation, i.e., ring ion formation which may take place in the silicate melts.

The significance of $k$ 's, which were taken to be adjustable parameters in the foregoing theories, was discussed by Masson ${ }^{12)}$ and Gaskell. ${ }^{16)}$ Also, extention of the above theories to ternary silicate melts was reviewed by Masson ${ }^{15)}$ and Yokokawa. ${ }^{17)}$

Further contribution to the second approach was made by Pretner ${ }^{18)}$ and more generally by Baes, Jr. ${ }^{19)}$ who took the intramolecular condensation reaction into account. Strain energy was assumed to arise when stoichiometry requires the formation of ring anions the member of which is less than six. Mixing of silicate anions was considered non-ideal, and the heat of mixing was assumed to originate from the contacts of $\mathrm{O}^{2-}$ with $\mathrm{O}^{-}$. The entropy of mixing was expressed in terms of the volume fraction instead of ion fraction of polyions the former of which is more appropriate when large polyions are present in the mixture. The Baes model involved three adjustable parameters, and fitted observed activities well over the full composition range in $\mathrm{LiF}-\mathrm{BeF}_{2}, \mathrm{FeO}-, \mathrm{MnO}-$, and $\mathrm{PbO}-\mathrm{SiO}_{2}$ systems. The distribution of complex anions was also derived, and the consequence was that the concentration in a given mixture of successive species with increasing number of $\mathrm{Si}$ or with increasing number of cross links fell logarithmically. As the composition was changed, however, the concentration of given species rised to a maximum and then fell.

An estimate of complex anions existing in quenched binary silicates was made by Yanagase and Suginohara ${ }^{20)}$ from infrared absorption study. The locations of absorption peak in the IR spectra shifted continually with $x_{\mathrm{SiO}_{2}}$ for $\mathrm{PbO}-\mathrm{SiO}_{2}$ whereas the shift was discontinuous for $\mathrm{Na}_{2} \mathrm{O}_{-}, \mathrm{CaO}_{-}, \mathrm{BaO}_{-}$, and $\mathrm{ZnO}-$ $\mathrm{SiO}_{2}$, suggesting the existence of $\mathrm{SiO}_{4}^{4-}, \mathrm{Si}_{2} \mathrm{O}_{7}^{6-}$, $\mathrm{Si}_{n} \mathrm{O}_{3 n}^{2 n-}, \mathrm{Si}_{2 n} \mathrm{O}_{5 n}^{2 n-}$ and/or $\mathrm{Si}_{4 n} \mathrm{O}_{9 n}^{2 n-}$.

A method for the gas-chromatographic separation of silicate anions was first described by Lent $z^{21)}$ who used a mixture of hexamethyldisiloxane, $\mathrm{HCl}$, and water to prepare the trimethylsilyl derivatives according to

$$
\begin{aligned}
& \left(\mathrm{CH}_{3}\right)_{3} \mathrm{Si} \cdot \mathrm{O} \cdot \mathrm{Si}\left(\mathrm{CH}_{3}\right)_{3}+\mathrm{HCl} \\
& =\left(\mathrm{CH}_{3}\right)_{3} \mathrm{SiCl}+\left(\mathrm{CH}_{3}\right)_{3} \mathrm{SiOH}
\end{aligned}
$$

The trimethylsilyl derivatives of silicate anions under-

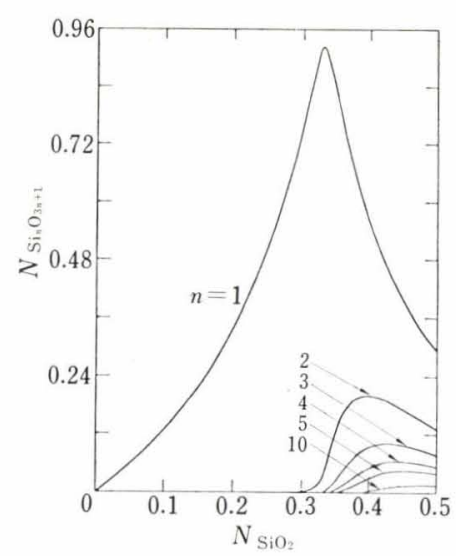

Fig. 4. Calculated ionic distributions for $\mathrm{CaO}-\mathrm{SiO}_{2}$ melts at $1600^{\circ} \mathrm{C}^{14)}$ 
went resolution by gas-liquid partition chromatography. Sodium silicate solutions having $\mathrm{Na} / \mathrm{Si}$ ratio of $4 / 1$ to $0.6 / 1$ were found to contain $\mathrm{SiO}_{4}^{4-}, \mathrm{Si}_{2} \mathrm{O}_{7}^{6-}$, $\mathrm{Si}_{3} \mathrm{O}_{10}^{8-}, \mathrm{Si}_{4} \mathrm{O}_{12}^{8-}$, and poly-silicate structures. However, side-reactions were found to occur in his method. This difficulty was adequately eliminated from direct trimethylsilylation proposed by Goetz and Masson ${ }^{22,23)}$ which was employed by Smith and Masson ${ }^{24)}$ to determine complex anions in quenched $\mathrm{CoO}-\mathrm{SiO}_{2}$ glass the composition of which was close to $\mathrm{CO}_{4} \mathrm{Si}_{3} \mathrm{O}_{10}$. As in the above sodium silicate solutions, monomer, dimer, trimeric chain, and tetrameric ring were identified. The same species were also found in quenched lead orthosilicate glass.

Regarding the theories of ionic distribution so far presented, although considerable progress has been made, all suffer from insufficient steric consideration. On the other hand, IR-method and direct trimethylsilylation are promising but still inadequate because of poor resolution of absorption peaks and of modification of anions upon extraction, respectively.

The above discussions have dealt only with the distribution of silicate anions and oxygen ion in slag melts which do not contain amphoteric cations such as $\mathrm{Fe}^{3+}$ and $\mathrm{Al}^{3+}$. The cations of basic and acidic oxides are known to occupy, respectively, octahedral and tetrahedral sites in the structure of corresponding oxides. However, the amphoteric cations can occupy both sites, i.e., the coordination of oxygen ion, the activity of which determines slag-metal equilibria, around the amphoteric cations changes with the basicity, or more exactly, with the activity of oxygen ion of the slag melts. This is of particular metallurgical interest since $\mathrm{Fe}_{2} \mathrm{O}_{3}$ and $\mathrm{Al}_{2} \mathrm{O}_{3}$ function both as basic and acidic oxide depending on the basicity.

Theoretical model to account for the thermodynamic properties of melts consisting of amphoteric cations has been given for $\mathrm{FeO}-\mathrm{Fe}_{2} \mathrm{O}_{3}$ melt by Takeuchi and Furukawa, ${ }^{25)}$ and more recently by Hagemark and Flood. ${ }^{26)}$ The two models, particularly the latter, reproduced experimental data satisfactorily. However, the coordination of $\mathrm{Fe}^{3+}$ and $\mathrm{Al}^{3+}$ in silicate melts has not yet been theoretically interpreted.

Optical absorption studies by Bates, ${ }^{27}$ ) Kurkjian and Sigety, ${ }^{28)}$ and Ito and Goto ${ }^{29)}$ on quenched glasses indicated that $\mathrm{Fe}^{3+}$ in $\mathrm{Na}_{2} \mathrm{O}-\mathrm{SiO}_{2}$ and $\mathrm{Na}_{2} \mathrm{O}-\mathrm{P}_{2} \mathrm{O}_{5}$ is in tetrahedral and octahedral sites, respectively. Tetrahedral coordination of $\mathrm{Fe}^{3+}$ in $\mathrm{Na}_{2} \mathrm{O}-\mathrm{SiO}_{2}$ was confirmed also by Mössbauer Spectrometry carried out by Frischat, ${ }^{30)}$ Frischat and Tomandl, ${ }^{31)}$ Pargamin, ${ }^{32)}$ and Lupis. ${ }^{33)}$ In $\mathrm{CaO}-\mathrm{SiO}_{2}$ melts, $\mathrm{Fe}^{2+}$ and a portion of $\mathrm{Fe}^{3+}$ occupied tetrahedral sites, whereas the balance of $\mathrm{Fe}^{3+}$ was in octahedral sites. Behavior of $\mathrm{Al}^{3+}$ in $\mathrm{CaO}-\mathrm{SiO}_{2}$ melts was also studied by IR spectra. ${ }^{34-36)}$ These data, if extended to slags with systematically changing compositions, will provide additional information on the structure of slags.

Action of fluorides is also important to control the viscosity of metallurgical slags. Formation of Si-F bond upon addition of fluorides to silicate melts according to

$$
\begin{aligned}
(\rightarrow \mathrm{Si} & -\mathrm{O}-\mathrm{Si}-\mathrm{O}-\mathrm{Si}<+\mathrm{CaF}_{2} \\
= & \left.\rightarrow \mathrm{Si}-\mathrm{O}^{-} \mathrm{Ca}^{2+} \mathrm{O}^{-}-\mathrm{Si}<\mathrm{F}+\rightarrow \mathrm{Si}-\mathrm{F}\right)
\end{aligned}
$$

was suggested, ${ }^{37)}$ but not supported. ${ }^{36,38)}$ Instead, fluorides are being considered to function only as a diluent of silicate melts. On the other hand, why addition of a few percents of fluorides yields marked decrease in the viscosity of neutral to acid slags is difficult to conceive on the basis of the latter mechanism. Function of fluorides in silicate and aluminate slags is open to a future investigation.

\section{Viscous Flow of Silicate Melts}

In iron- and steel-making practices, the viscosity of slag melts is usually maintained below a few poises to enhance mass transport of impurities being removed from metal phase in contact. For teeming practices, more viscous slags are employed to prevent physical entrainment of slags into molten metals and to provide glassy slag films on the surface of solidifying steel to give better surface. ${ }^{2,39)}$ Comprehensive compilation of viscosity of slags of metallurgical importance is available elsewhere. ${ }^{40)}$

General features are that the viscosity decreases with increase of temperature and the ratio of network modifier to network former, reflecting distintegration of complex anion which (or agglomerate of which) constitutes a flow unit. Although major contribution to the viscosity of silicate melts comes from the distribution of polyions in the melts, interaction between polyions and surrounding cations was believed by Ito and Yanagase ${ }^{41)}$ not to be neglected for $\mathrm{PbO}-\mathrm{SiO}_{2}$ melts. They found, as shown in Fig. 5, that when $\mathrm{PbO}$ in the melt was partially replaced by alkali oxide $\left(\mathrm{M}_{2} \mathrm{O}\right)$ or alkali earth oxide (MO), the viscosity of the melts increased with increasing radii of $\mathrm{M}^{+}$or with decreasing radii of $\mathrm{M}^{2+}$.

Temperature dependence of the viscosity, $\eta$, of slag melts can be expressed, within a narrow span of temperature, by an Arrhenius type equation at temperatures well above the glass transition point, $T_{g}$, as,

$$
\eta=\eta_{0} \exp \left(E_{\eta} / k_{B} T\right)
$$

(where, $k_{B}$ : the Boltzmann constant), which indicates the viscous flow to be a thermally a ctivated process. On this basis, Eyring et al. ${ }^{42)}$ derived an expression for the viscosity in terms of the theory of absolute reaction rates which will be discussed in section $I I I, 1$.

Semi-empirical interpretation of an observed cor-

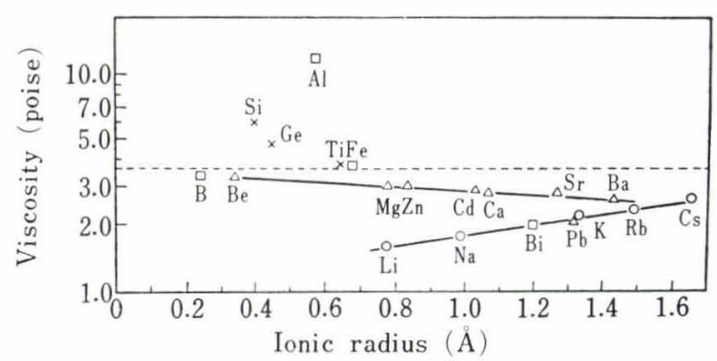

Fig. 5. Viscosity of $\mathrm{PbO}-\mathrm{SiO}_{2}-\mathrm{Metal}$ Oxide ( $\mathrm{MO}$ or $\mathrm{M}_{2} \mathrm{O}$ ) melts plotted against radius of metal ion of the metal oxide $\left(\mathrm{MO} \text { or } \mathrm{M}_{2} \mathrm{O}\right)^{42}$ ) 


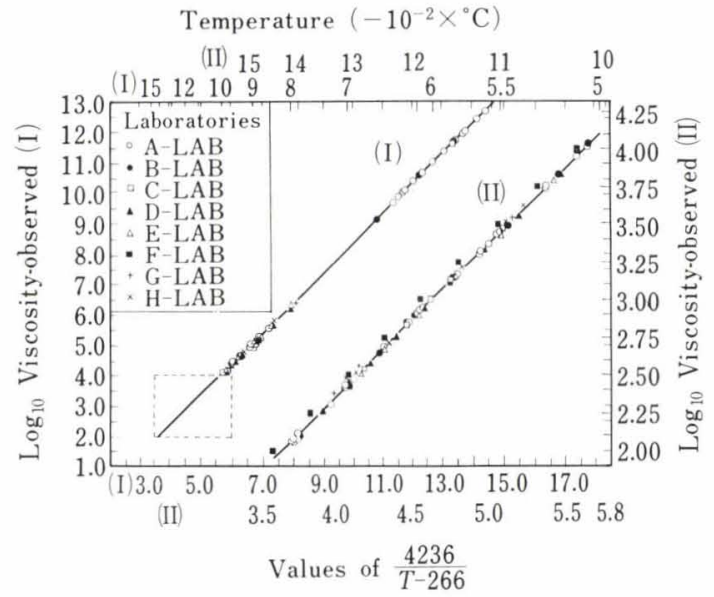

Fig. 6. Observed value of $\log$ viscosity of standard glass No. $710\left(\mathrm{SiO}_{2} 70.5, \mathrm{Na}_{2} \mathrm{O} 8.7, \mathrm{~K}_{2} \mathrm{O} 7.7, \mathrm{CaO} 11.6\right)$ plotted against a function of temperature 4236/ $\left(T^{\circ} \mathrm{C}-266\right)^{44)}$

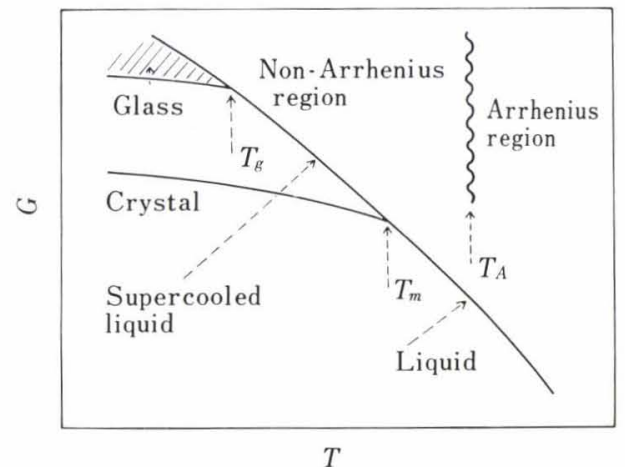

Fig. 7. Arrhenius type to non-Arrhenius type transition of viscous flow as illustrated on a schematic phase diagram of one component system. $T_{g}$ : glass transition temperature, $T_{m}$ : melting temperature, $T_{A}$ : Arrhenius temperature, $G$ : Gibbs free energy

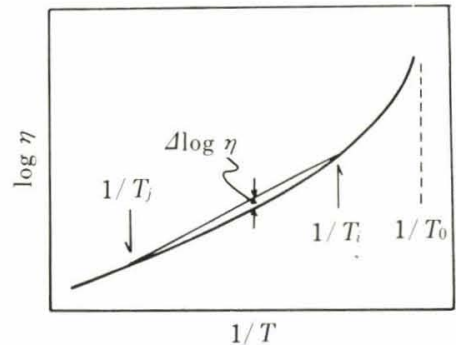

Fig. 8. Schematic illustration of non-Arrhenius behavior of viscosity

relation between $E_{\eta}$ and melting point was attempted elsewhere ${ }^{43)}$ for ionic melts.

However, the apparent activation energy, $E_{\eta}$, in Eq. (11) has been observed in many cases to increase with decreasing temperature if temperature span is considerably extended. The departure from Eq. (11) can be represented by

$$
\left.\eta=\eta_{0} \exp [\text { const./(T-T })\right]
$$

where, $\eta_{0}$ and $T_{0}$ are constants for a system. Equation (12) is known to cover wider variety of slag melts at larger span of temperatures and hence larger span of viscosity, e.g., $10^{2}$ to $10^{13}$ poises for a silicate as shown in Fig. 6. ${ }^{44)}$

The lowest temperature at which the experimental viscosity data follow the Arrhenius type equation was called after Davis and Matheson ${ }^{45)}$ as Arrhenius temperature, $T_{A}$. Relation between $T_{g}, T_{A}$, and Arrhenius type or non-Arrhenius type behavior of viscosity is given schematically on a phase diagram, Fig. 7. Modelistic approaches to derive non-Arrhenius type viscosity expressions will be given in section $I I I, 2$ to 5 in which applications of the expressions to silicate melts will be also discussed.

The validity of Eq. (12) was first revealed for silicate melts ${ }^{46,47)}$ then for organic polymer melts ${ }^{48}$ and melts consisting of small molecules. ${ }^{49,50)}$ It is worth considering why Eq. (12) was found suitable for silicate melts as the first instance, since this seems to be relevant to the nature of the viscous flow of the silicate melts. Relation between $\log \eta$ and $1 / T$ as given by Eq. (12) is shown in Fig. 8. Log $\eta$ is proportional to $1 / \mathcal{T}$ at $T \gg T_{0}$, whereas it diverses to infinity as $T$ approaches to $T_{0}$. Non-Arrhenius behavior can be recognized only when the value of $\Delta \log \eta$ exceeded the error of measurement at $T_{i}<T<T_{j}$. It is obvious from Fig. 8 that $T_{A}$, which is known to depend upon substances, ${ }^{45)}$ varies with the accuracy of viscosity measurement as well as the span of temperatures employed for the measurements. Non-Arrhenius behavior as represented by Eq. (12) can be observed if the error of measurement is much smaller than $\Delta \log \eta$. This can be attained if the measurement is extended to a temperature sufficiently close down to $T_{0}$. The measurement below melting point, $T_{m}$, is usually inhibited by crystallization of melt. However, silicate melts often retains vitreous state and hence make viscosity measurement possible even for supercooled liquid. This is behind why Eq. (12) has first been found for silicate melts.

Non-equilibrium statistical mechanics has been successful in describing the viscosity of rare gas liquids ${ }^{51)}$ and liquid metals ${ }^{52}$ ) in both of which flow unit can be regarded spherical. Many difficulties arise when this approach is extended to treat liquids in which flow unit is polyatomic. In fact, few attempts have been published for silicate melts along this line. In view of the theoretical importance, however, brief survey of this approach will be given in section $I I I, 6$.

\section{Theory of Absolute Reaction Rates}

Eyring and his co-workers ${ }^{42}$ ) applied the theory of absolute reaction rates to the problem of the viscosity of liquid. Two adjacent layers of molecules were considered in a liquid, and sliding motion of one layer with respect to the other under the influence of an applied force was assumed to involve the passage of a molecule from one equilibrium position to another such position in the same layer. The difference in the specific rate of the passage between forward direction, i.e., direction of the force, and backward direction was evaluated to give 


$$
\eta=\frac{h \mathcal{N}}{V} \cdot \frac{F}{F *} \exp \left(\varepsilon_{0} / k_{B} T\right)
$$

where, $h$ is the Planck constant, $V$ is the molar volume, $\mathcal{N}$ is the Avogadro number, $F$ and $F^{*}$ are the partition function, for unit volume, of the molecule in the initial and activated state, and $\varepsilon_{0}$ is the activation energy for the passage at $0{ }^{\circ} \mathrm{K}$. Utilizing the identity

$$
\frac{F}{F^{*}} \exp \left(\varepsilon_{0} / k_{B} T\right)=\exp \left(\Delta G^{*} / R T\right)
$$

Eq. (14) turns into

$$
\begin{aligned}
\eta & =\frac{h \mathcal{N}}{V} \exp \left(\Delta G^{*} \mid R T\right) \\
& =\left[\frac{h \mathcal{N}}{V} \exp \left(-\Delta S^{*} \mid R\right)\right] \exp \left(\Delta H^{*} \mid R T\right) \ldots
\end{aligned}
$$

where, $\Delta G^{*}, \Delta H^{*}$, and $\Delta S^{*}$ are, respectively, the free energy, enthalpy, and entropy of activation. Equation (15) is equivalent to Eq. (11) for a narrow temperature span in which $V, \Delta S^{*}$, and $\Delta H^{*}$ are practically constant.

Estimation of $F$ and $F^{*}$ in terms of a cell model of liquid yielded an alternative expression given by

$$
\eta=\left(\frac{\mathcal{N}}{V}\right)^{2 / 3} \frac{c R T}{\Delta E_{\text {vap }}}\left(2 \pi m k_{B} T\right)^{1 / 2} \exp \left(\varepsilon_{0} / k_{B} \mathcal{T}\right)
$$

where $c$ is the packing number (=2 for cubic packing), $m$ is the mass of molecule, and $\Delta E_{\mathrm{vap}}$ is the molar energy of vaporization

These concepts were incorporated by Bockris and his colleagues ${ }^{53,54)}$ to discuss the mechanism of viscous flow of silicate melts. Assuming $\mathrm{SiO}_{2}$ molecule to be the flow unit in pure fused silica, the free energy of activation in Eq. (15) was calculated from observed viscosity to be $90 \mathrm{kcal} \mathrm{mol}^{-1}$. This was shown ${ }^{53)}$ to be in good agreement with $87 \mathrm{kcal} \mathrm{mol}^{-1}$ separately calculated from the empirical relationship ${ }^{55)}$

$$
\Delta G^{*} \cong \Delta E_{\mathrm{vap}} / 2.4
$$

where heat of vaporization, $\Delta E_{\mathrm{vap}}$, was roughly estimated as one half of the energy for breaking four $\mathrm{Si}-\mathrm{O}$ bonds. The agreement was taken to be an evidence to support the assumption.

Bockris et al. ${ }^{54)}$ subsequently showed that the addition of small amount of metal oxides to fused silica melts results in a marked decrease of $E_{\eta}$ as shown in Fig. 9. The addition of metal oxides was considered to break $\mathrm{Si}-\mathrm{O}$ bonds, introducing "weak points" into silica network. Also, $\mathrm{Si}-\mathrm{O}$ bonds near the metal ion are weakened owing to the polarizing effect of cation. These contributions were thought to decrease the energy to form flow unit such as $\mathrm{SiO}_{2}$ molecule or the entity

$$
\text { - } \mathrm{O}-\mathrm{Si}-\mathrm{O}^{\tilde{o}-} \mathrm{K}^{+}
$$

and hence decrease the activation energy of the viscous flow with the addition of metal oxides.

When the addition of metal oxides exceeded a critical value, c.a. $10 \mathrm{~mol} \%$ for alkali oxides or c.a. 20 $\mathrm{mol} \%$ for alkaline earth oxides, three dimensional network of $\mathrm{SiO}_{2}$ was believed to be broken into dis- crete silicate anions, which constitute flow units in the melts. Further addition of the metal oxides were to make the size of the anions smaller. However, this effect had limited influence on $E_{\eta}$ on the basis of Fig. 9.

It must be noted that straight forward application of Eyring's viscosity expression to silicate melts is obviously inadequate in that it fails to explain considerable departure of temperature dependence of the viscosity from Arrhenius behavior even if pre-exponential factor, which contains a temperature dependent $T^{3 / 2}$ terms, is taken into account. This clearly indicates that the activation energy for a silicate melt cannot be uniquely determined over a wide span of temperature.

\section{Free Volume Theory}

The above inadequacy stimulated the application of free volume theory to interpret the viscosity of silicate melts. Doolittle ${ }^{56)}$ showed empirically that the viscosity can be related to the free volume of a liquid as

$$
\eta=A_{1} \exp \left(B V_{0} / V_{f}\right)
$$

where, $V_{0}$ is close packed volume, $V_{f}$ is the free volume, and $A_{1}$ and $B$ are constants characteristic of the liquid.

Cohen and Turnbull ${ }^{57}$ ) provided solid theoretical foundation of Eq. (18). They assigned a free volume to each of the flow units in a hard sphere melt, and explicitly calculated the distribution of the free volume by maximizing the configurational entropy of the free volume at a given total free volume.

Resulting probability of finding a free volume, $v$, nearby was given by

$$
P(v)=\left(r / v_{f}\right) \exp \left(-\gamma v / v_{f}\right)
$$

where, $v_{f}$ is average free volume/flow unit, $\gamma$ is a correction factor ( $\frac{1}{2}$ to 1 ) for the overlapping between free volumes. Assuming that a minimum free volume, $v^{*}$, is needed for a jump of a flow unit to occur, jump probability, $P_{v}$, was calculated as

$$
P_{v}=\int_{v^{*}}^{\infty} P(v) d v=\exp \left(-\gamma v^{*} / v_{f}\right)
$$

The viscosity was assumed to be inversely proportional to the diffusional jump probability, and hence was given by

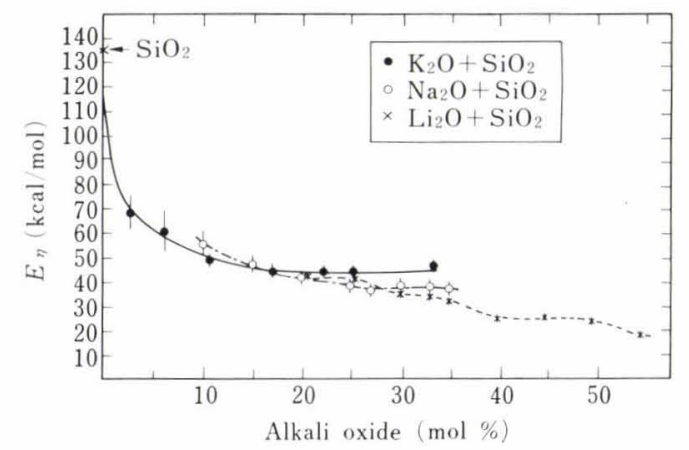

Fig. 9. Activation energy of viscous flow for $\mathrm{M}_{2} \mathrm{O}-\mathrm{SiO}_{2}$ systems as a function of composition 


$$
\eta=A_{2} / P_{v}=A_{2} \exp \left(\gamma v^{*} / v_{f}\right)
$$

where temperature dependence of $A_{2}$ is usually regarded much less than that of the exponential term. Equation (21) is identical to Eq. (18). When a product of thermal expansion coefficient, $\alpha$, and volume, $V$, is essentially constant for a melt over a temperature range in question, total free volume may be approximated by

$$
V_{j}=\alpha V\left(T-T_{0}\right)
$$

where, $T_{0}$ is a temperature at which $V_{f}$ becomes zero. Then, one gets from Eqs. (21) and (22)

$$
\eta=A_{2} \exp \left(\frac{C}{T-T_{0}}\right), \quad C=\mathcal{N}_{\gamma} v^{*} / \alpha V
$$

where, $\mathcal{N}$ is the number of flow units. Equation (23) is equivalent to Eq. (12), and reduces to an Arrhenius type equation at $T \gg T_{0}$.

It is interesting to note that Eq. (23) is valid for monoatomic liquids. ${ }^{58)}$ Since Eq. (23) gives marked increase in viscosity at $T \cong T_{0}$, monoatomic liquids should also exhibit viscosity of about $10^{13}$ poises $^{47}$ ) for transition from supercooled to glassy state provided that crystallization is prevented. The existence of glassy state for monoatomic liquids has long been in question, ${ }^{59)}$ but recent observation of glassy state for simple liquids such as $\mathrm{H}_{2} \mathrm{O},{ }^{60} \mathrm{CHCl}_{3},{ }^{61)} \mathrm{CCl}_{4}{ }^{62)}$ and etc. may suggest the existence of glassy state for monoatomic liquids.

From the above discussions, existence of glassy state for highly basic silicate melts could be predicted because symmetric $\mathrm{SiO}_{4}^{4-}$ coordinated by much smaller cations can be regarded monoatomic constituent of the melts. Then, it is of much theoretical interest to examine the validity of Eq. (23) for supercooled highly basic silicate melts.

The validity of Eq. (21) was examined by Kumar ${ }^{63)}$ for fused boric oxide, alkali borates, barium borate, and alkali silicates. If flow units in these melts were assumed to be of spherical symmetry and to move at kinetic velocity of gas, Eq. (21) becomes, after some manupulation, to be

$$
\begin{aligned}
\log \eta / T^{1 / 2} & =\log A_{2}^{\prime}+\gamma v^{*} / v_{f} \ldots \ldots \\
A_{2}^{\prime} & =1 / 3 \cdot\left(m k_{s} / 3 \pi g a^{2}\right)^{1 / 2}
\end{aligned}
$$

where, $m$ and $a$ are mass and diameter of the flow unit, and $g$ is a steric factor. Plot of $\log \eta / T^{1 / 2}$ against $1 / v_{f}$ showed straight lines which confirmed the validity of Eq. (24) for these melts. The slope and intercept of these lines gave $\log A_{2}^{\prime}$ and $\gamma v^{*}$, respectively. Decrease of $r v^{*}$ with increasing alkali oxide concentration was found for alkali borates, as shown in Fig. 10, indicating the disintegration of anions. Major flow species in alkali silicate melts was estimated to be $\mathrm{SiO}_{4}^{4-}$ and/or $\mathrm{Si}_{2} \mathrm{O}_{7}^{6-}$ on the basis of the value thus obtained for $r v^{*}$ which was 4 to 7 folds of the size of $\mathrm{O}^{2-}$. This compares with the Masson theory which predicted that most abundant silicate anion in alkali silicate melts in the vicinity of meta-silicate composition is $\mathrm{SiO}_{4}^{4-}$. Also, the value of $A_{2}^{\prime}$ theore-

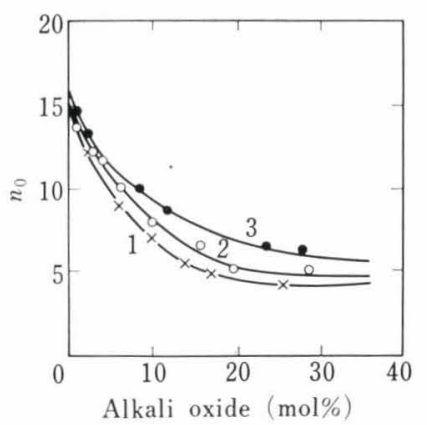

Fig. 10. Composition vs. number of oxygen atoms in a flow unit in $\mathrm{M}_{2} \mathrm{O}-\mathrm{B}_{2} \mathrm{O}_{3}$ systems with assumed $\gamma$ of 0.9 : 1; $\mathrm{Li}_{2} \mathrm{O}-\mathrm{B}_{2} \mathrm{O}_{3}, 2 ; \mathrm{Na}_{2} \mathrm{O}-\mathrm{B}_{2} \mathrm{O}_{3}, 3 ; \mathrm{K}_{2} \mathrm{O}-\mathrm{B}_{2} \mathrm{O}_{3}{ }^{62}$ )

tically calculated by use of Eq. (25) was in good agreement with those experimentally obtained. Exceptions were for barium borates and vitreous silica for both of which observed $A_{2}^{\prime}$ was much larger.

Difficulties involved in the above theory are that the value of $T_{0}$ cannot uniquely be determined by the theory ( $\mathcal{T}_{0}$ is an adjustable parameter, instead) and that $d \ln \eta / d T$ becomes zero at constant volume in contrast to experimental observation.

\section{Hybrid Theory}

Foregoing difficulties were to some extent resolved by Macedo and Litovitz, ${ }^{64)}$ who introduced another probability, $P_{e}$, of attaining sufficient energy to surmount the energy barrier before a jump of a flow unit to occur, and worked out a hybrid equation combining aspects of both the Eyring and Cohen and Turnbull theories. Resulting expression is

$$
\eta=A_{3} / P_{v} P_{e}=A_{3}^{\prime} \exp \left(E_{v}^{*} / R T+\lambda V_{0} / V_{f}\right) \ldots \ldots
$$

where, $E_{v}^{*}$ is the activation energy for jumping. This reduces to the Cohen-Turnbull equation when $V_{0} /$ $V_{f} \gg E_{v}^{*} \mid R T$, and to an Arrhenius type equation with some contribution of free volume retained (when $T \gg T_{0}$ ) or without that (when $\alpha \cong 0$, thus $V_{f}=$ const.).

They were able to reproduce observed $\eta$ vs $T$ relationship for $\mathrm{GeO}_{2}-, \mathrm{SiO}_{2}-$, silicate-, and borate-melts with sufficient accuracy by choosing appropriate values for $A_{3}^{\prime} \alpha, V, V_{0}$, and $E_{v}^{*}$. In many cases, $V_{0}$ 's thus chosen were found to be consistent with the volume of closest-packing. The values of $\alpha$ 's thus obtained for $\mathrm{SiO}_{2}$ and $\mathrm{Na}_{2} \mathrm{O} \cdot \mathrm{CaO} \cdot \mathrm{SiO}_{2}$ glass were close to those correspondingly estimated from experimental observation. Also, concentration dependence of $\eta$ of $\mathrm{Na}_{2} \mathrm{O}-$ $\mathrm{B}_{2} \mathrm{O}_{3}$ melts was explained by taking $1 / E_{v}^{*}$ to be equal to $x_{\mathrm{Na}_{2} \mathrm{O}} / E_{v \mathrm{Na}_{2} \mathrm{O}}^{*}$ plus $x_{\mathrm{B}_{2} \mathrm{O}_{3}} / E_{v \mathrm{~B}_{2} \mathrm{O}_{3}}^{*}$. Derivation of the Macedo-Litovitz equation on the basis of statistical mechanics was carried out by Chung. ${ }^{65)}$ In the Macedo-Litovitz equation, $V_{0}$ may depend upon temperature and pressure as it was so for borosilicate glass. ${ }^{6}$ ) If so, use of such hybrid equation lacks its original meaning. The value of $T_{0}$ cannot uniquely be determined, too.

\section{Cooperative Motion Theory}

It is not easy to conceive the significance of activated jumping for some silicate melts in which a flow 
unit (complex anion) is fairly large, forming long chain or network. In reality, motion of a flow unit should involve for viscous flow to occur cooperative motion of surrounding flow units.

This was first taken into account by Adam and Gibbs. ${ }^{67)}$ They considered a macroscopic system to be an isobaric-isothermal ensemble of $\mathcal{N}_{S}$ independent, equivalent, and distinguishable subsystems composed of $z$ molecular segments (flow units) each. Upon a sufficient fluctuation in energy, the subsystem can cooperatively rearrange into another configuration independently of its environment. Among $\mathcal{N}_{s}$ subsystems, $n_{s}$ were allowed a cooperative rearrangement and $\mathcal{N}_{s}-n_{s}$ were in states not allowing a transition. Denoting the Gibbs free energy for the former and the latter to be $G^{\prime}$ and $G$ and the difference to be $z \Delta \mu$, the cooperative transition probability, $P$, was given by

$$
\begin{aligned}
P & =A_{4} n_{s} / \mathcal{N}_{s}=A_{4} \exp \left[-\left(G^{\prime}-G\right) \mid k_{\mathrm{B}} T\right] \\
& =A_{4} \exp \left(-z \Delta \mu / k_{\mathrm{B}} \mathcal{T}\right) \ldots \ldots \ldots \ldots \ldots \ldots \ldots \ldots \ldots
\end{aligned}
$$

where $A_{4}$ is a constant. The average transition probability, $\bar{P}$, which is inversely proportional to $\eta$, was given by the summation of $P$ over subsystems the size of which is larger than $z^{*}$ :

$$
\begin{aligned}
1 / \eta \propto \bar{P} & =\sum_{z=z^{*}}^{\infty} A_{4}\left[\exp \left(-\Delta \mu / k_{\mathrm{B}} \mathcal{T}\right)\right]^{z} \\
& =A_{4}^{\prime} \exp \left(-z^{*} \Delta \mu / k_{\mathrm{B}} T\right) \ldots \ldots
\end{aligned}
$$

Here, $z^{*}$ is a critical lower limit to the size of cooperative regions that can yield nonzero transition probability. If the macroscopic system consisted of 1 mole of segments, the configurational entropy of the macroscopic system $\left(S_{c}\right)$ was given by $\mathcal{N}_{s} s_{c}$ where $s_{c}$ is the configurational entropy of a subsystem of $z$ segments. Noting that $s_{c}$ and critical value of which are given by

$$
\begin{aligned}
s_{c} & =k_{\mathrm{B}} \ln \left(P_{c}\right)^{z / N_{A}}, \\
s_{c}^{*} & =k_{\mathrm{B}} \ln \left(P_{c}\right)^{z^{*} / N_{A}}
\end{aligned}
$$

where $P_{c}^{1 / N_{A}}$ is average number of configurations and $\mathcal{N}_{A}$ is the Avogadro number, one obtains $z^{*}$ to be equal to $\mathcal{N}_{A} s_{C}^{*} / S_{c}$. This $z^{*}$ was inserted into Eq. (28) to give

$$
\eta=A_{4}^{\prime \prime} \exp \left[\left(\Delta \mu s_{c}^{*} / k_{B}\right)\left(1 / T S_{c}\right)\right]
$$

where the first term in the square bracket is a constant.

If the difference in the heat capacity between equilibrium liquid state and glassy state of silicates $\left(\Delta C_{p}\right)$ is assumed constant over the temperature range in question, one has

$$
\begin{aligned}
S_{c}(T)-S_{c}\left(T_{2}\right) & =\int_{T_{2}}^{T}\left[\Delta C_{p}(T) / T\right] d T \\
& =\Delta C_{P} \ln \left(T / T_{2}\right) \ldots \ldots
\end{aligned}
$$

Further, if $T_{2}$ is chosen to make $S_{c}\left(T_{2}\right)$ to be zero and $\left(T-T_{2}\right)$ is sufficiently smaller than $T_{2}$, one gets $T S_{c}$ $(T)=\Delta C_{p}\left(T-T_{2}\right)$ from which and Eq. (30) the following results:

$$
\eta=A_{4}^{\prime \prime} \exp \left\{\left(\Delta \mu \Delta s_{c}^{*} \mid k_{B}\right)\left[1 / \Delta C_{p}\left(T-T_{2}\right)\right]\right\}
$$

Adam and Gibbs ${ }^{67)}$ determined the values of $\Delta \mu s_{c}^{*} \mid k_{B}$ and $T_{g} / T_{2}$ for various liquids from experiments. The latter value was in good agreement with $T_{g} / T_{2}$ of 1.3 which was separately obtained by calorimetry using the following relation:

$$
\begin{aligned}
& S_{c}\left(\mathcal{T}_{g}\right)=\left[S_{c} \text { (glass) }-S_{c}(\text { crystal })\right]_{T=0} \\
& =\int_{T_{2}}^{T_{g}}\left(\Delta C_{p} / T\right) d T
\end{aligned}
$$

Also, the value of $\Delta \mu$ was consistent with estimated potential barriers. Ambiguities in the physical significance of $T_{0}$ and $E_{v}^{*}$ involved in the MacedoLitovitz equation have been resolved by the concept of rearrangement of segments. However, the validity of this theory has not yet fully tested for silicate melts. In order to get an equation of the type of Eq. (12), which covers wide span of temperatures, approximations made for going from Eq. (30) to (32) are obviously insufficient. Thus, it is not clear for silicate melts whether or not Eq. (30) yields a type of Eq. (12) covering temperature much higher than $T_{2}$. Further development to obtaining reliable expression for $S_{c}$ is awaited.

\section{Environmental Relaxation Theory}

The importance of the cooperative nature of motion in the mechanism of viscous flow was also revealed by Macedo and his colleagues in a different way. Macedo and Napolitano ${ }^{66}$ compared observed with calculated viscosities of $\mathrm{B}_{2} \mathrm{O}_{3}$ melts over the range of $10^{2}$ to $10^{14}$ poises and found that all foregoing theoires are inadequate to account for the observed data as shown in Fig. 11. Apparent activation energy, $E_{\text {app }}$, calculated from the data as $R d \ln \eta / d(1 / T)$ is reproduced in Fig. 12. $E_{\text {app }}$ was constant below $320^{\circ} \mathrm{C}$ and above $800^{\circ} \mathrm{C}$ whereas it increased in between with decreasing temperature. This corresponded to the deviation of viscosity from an Arrhenius behavior. All foregoing theories were so far not aware of, and hence incapable to explain the Arrhenius type behavior at the lower temperatures. In this connection, Tauke, Litovitz, and Macedo ${ }^{68}$ ) measured velocity and absorption of ultrasonic wave in $\mathrm{B}_{2} \mathrm{O}_{3}$ melts, and determined the distribution, $g(\tau)$, of relaxation time, $\tau$, the results being depicted in Fig. 13. The distribution was insensitive to temperature above $800^{\circ} \mathrm{C}$, but it became broader with decreasing temperature. These observation indicate that the departure from the Arrhenius type behavior of viscosity at 320 to $800^{\circ} \mathrm{C}$ may be attributable to the broadening of $g(\tau)$ with decreasing temperature. Regarding this, Simmons and Macedo $^{69)}$ proposed environmental relaxation model for the viscous flow of liquids. They considered that in a liquid there is distribution of relaxation time which is determined by the structure of liquid within a radius $r_{0}$ around a flowing species (structural relaxation range). With decreasing temperature, local structure of liquid becomes more orderly, and the size of the orderly structure or " micro-structure " was expressed by another radius $A$ (correlation length). Temperature dependence of $\Lambda$ yields three temperature regions, as shown in Fig. 14, with respect to the relative magnitude of $A$ to $r_{0}$. At higher temperatures, local struc- 
ture within $r_{0}$ does not change markedly irrespective of the location of the center of $r_{0}$ in the liquid because $r_{0} \gg \Lambda$. Consequently, $g(\tau)$ gets sharper. Small change in $A$ caused by temperature change does not affect $g(\tau)$ much since $r_{0} \gg \Lambda$ and $d r_{0} / d T$ was assumed negligibly small. At medium temperatures, the local structures, i.e., number of configurations, change markedly depending upon the choice of location of the structural relaxation range because at these temperatures $r_{0} \cong A$. This makes $g(\tau)$ quite sensitive to temperature. At lower temperatures where $r_{0} \ll A$, the location of $r_{0}$ will be mostly within the orderly structure, the "microstructure", and has little influence on the local structure, and hence the Arrhenius type dependence of viscosity on temperature results. This qualitatively explains the features of viscosity of $\mathrm{B}_{2} \mathrm{O}_{3}$ melts. Although lack of detailed knowledge on the size of the microstructure of silicate melts makes it impossible to quantitatively deduce viscosity expression from this model, it was successfully applied by Simmons, Mills, and Napolitano ${ }^{70)}$ to interpret the anomaly in the viscosity of two sodium-borosilicate glasses caused by concentration fluctuation nearby critical point for phase separation at which $A$, as given to be the radius of one separated phase in the other matrix phase, was available as a function of temperature. The values of $r_{0}$ for the two glasses, $7 \mathrm{Na}_{2} \mathrm{O}$. $23 \mathrm{~B}_{2} \mathrm{O}_{3} \cdot 70 \mathrm{SiO}_{2}$ and $4 \mathrm{Na}_{2} \mathrm{O} \cdot 13 \mathrm{~B}_{2} \mathrm{O}_{3} \cdot 2 \mathrm{Al}_{2} \mathrm{O}_{3} \cdot 81 \mathrm{SiO}_{2}$, were found to be 57 and $58 \AA$, respectively.

\section{Non-equilibrium Statiscomechanical Treatment}

Statistical mechanics of non-equilibrium state has

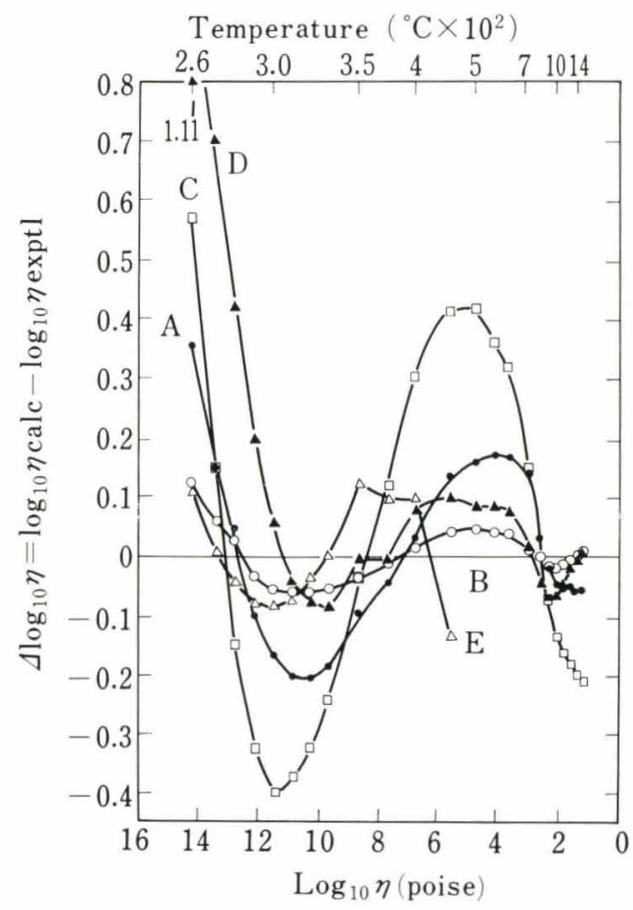

Fig. 11. Deviations between the observed log viscosity values and those calculated from the least-squares fit to several models for $\mathrm{B}_{2} \mathrm{O}_{3}$ glasses ${ }^{65}$ )

A; Fulcher, B; WLF, C; Ree, Ree and Eyring, D; Macedo and Litovitz, and E; Adam and Gibbs been developed by Rice and Kirkwood ${ }^{71)}$ to express short range force contribution to the viscosity of dense fluid in terms of local equilibrium pair correlation function, $g_{0}^{(2)}\left(r_{12}\right)$, and intermolecular potential, $u\left(r_{12}\right)$, as

$$
\eta_{R K}=\frac{m}{30 \zeta}(\mathcal{N} / V)^{2} \int r_{12}^{2}\left(u^{\prime \prime}+\frac{4}{r_{12}} u^{\prime}\right) g_{0}^{(2)}\left(r_{12}\right) d^{3} r_{12} \ldots
$$

where $m$ is the mass of a molecule, $\mathcal{N}$ is the number of molecules, $V$ is the volume, and the friction coefficient $\zeta$ is obtained from the mean frictional force as

$$
\zeta^{2}=(m \mathcal{N} / 3 V) \int \nabla_{r_{12}}^{2} u\left(r_{12}\right) g_{0}^{(2)}\left(r_{12}\right) d^{3} r_{12}
$$

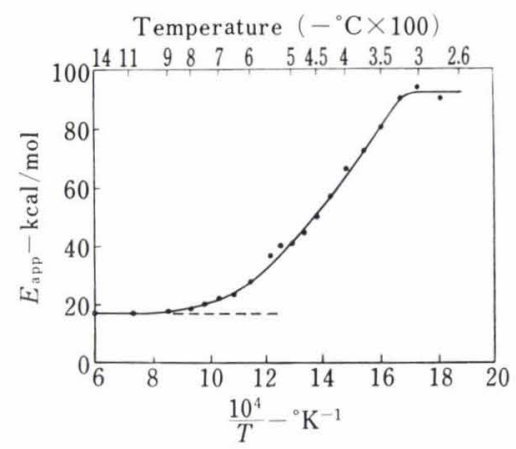

Fig. 12. Plot of apparent activation energies vs. temperature for $\mathrm{B}_{2} \mathrm{O}_{3}$ glass ${ }^{65}$ )

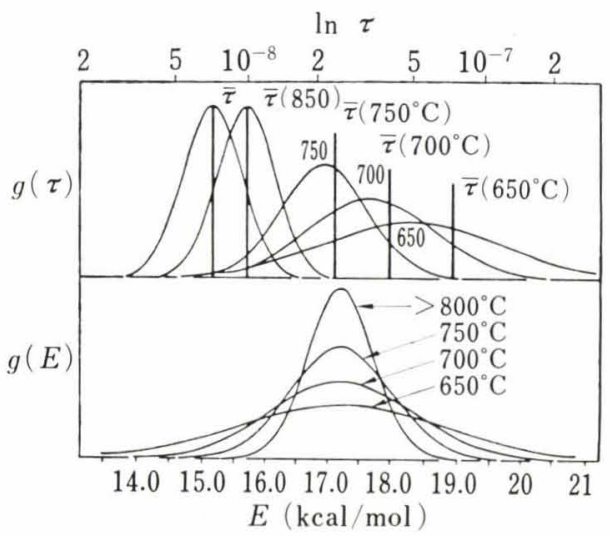

Fig. 13. Observed relaxation time spectrum and activation energy distribution for $\mathrm{B}_{2} \mathrm{O}_{3}$ glass ${ }^{65}$ )

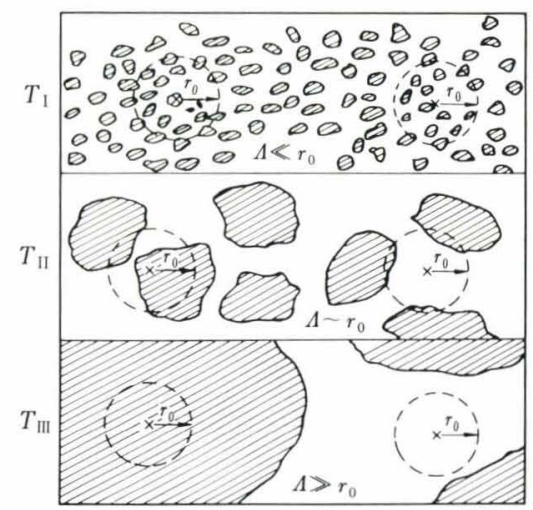

Fig. 14. Schematic illustration of the size of "micro-structure" $\left(\mathrm{r}_{\mathrm{o}}\right)$ relative to that of "structural relaxation range" $(\Lambda)$ at different temperatures $\left(T_{\mathrm{I}}>\right.$ $T_{\text {II }}>T_{\text {III }}{ }^{69)}$ 
For a melt constituting of cations and complex anions for which interionic potentials and spacial correlation functions are unavailable, straightforward application of the above small step diffusion formulation is extremely difficult. To resolve this, Nozaki and Shimoji ${ }^{72)}$ noticed that largest contribution to the value of the integration in Eqs. (34) and (35) arises at $r_{12}$ very close to the first peak, $r_{12}=a$, on $g_{0}^{(2)}\left(r_{12}\right)$. This was introduced in Eqs. (34) and (35) to get a simplified version,

$$
\eta=n a^{2} \zeta / 10, \quad n: \mathcal{N} / V
$$

to describe the viscosity observed for $\mathrm{Na}+\mathrm{NH}_{3}$ and $\mathrm{NH}_{4} \mathrm{I}+\mathrm{NH}_{3}$ systems. Eliminated in Eq. (30) were $u\left(r_{12}\right)$ and $g_{0}^{(2)}\left(r_{12}\right)$ which are usually unavailable for polyatomic liquids. Also neglected was a term

$$
\eta^{*}=(m / 15 \zeta)(\mathcal{N} / V)^{2} \int r_{12} u^{\prime}\left(r_{12}\right) g_{0}^{(2)}\left(r_{12}\right) d^{3} r_{12}
$$

which is too small, $\cong 2 \times 10^{-5}$ poises for $\mathrm{NH}_{3}$ at $-30^{\circ} \mathrm{C}$, to be reserved in Eq. (34).

The friction coefficient can also be connected with the self-diffusivity, $D$, by the Einstein relation:

$$
D=K T / \zeta \text {. }
$$

If the flow species can be regarded as hard spheres of diameter $\sigma$ and the first peak on $g_{0}^{(2)}\left(r_{12}\right)$ appears at $r_{12}=\sigma$, the number density of flow species can be expressed as

$$
1 / n=V / \mathcal{N} \cong \pi \sigma^{3} / 6 \xi
$$

where, $\xi$ is the packing factor. Substituting Eq. (39) into Eq. (36) gives

$$
\eta_{N S}=3 \zeta \xi / 5 \pi \sigma
$$

When soft portential is operating between the flow species,

$$
1 / n \cong \pi a^{3} / 6
$$

is a reasonable approximation for which the viscosity becomes

$$
\eta_{N S^{\prime}}=3 \zeta \xi^{1 / 3} / 5 \pi a
$$

This approach was applied by Ejima and Shimoji ${ }^{73)}$ to theoretically evaluate the viscosity of silicate melts. With values of $\zeta$ and $a$ derived respectively from the self-diffusivity of $\mathrm{Si}$ (as a constituent of flowing species) and from surface tension of corresponding melt, the viscosity of $\mathrm{CaO}-\mathrm{SiO}_{2}$ melt $(1: 1)$ was estimated to be about 1 poise which favorably compared with experimental observation, 3.9 poises.

\section{Concluding Remarks}

Foregoing modelistic theories for viscous flow can be classified in two categories. One is based upon the concept that viscous flow takes place by jumping of spherical flow units into neighbourring holes. The Eyring, Cohen-Turnbull, and Macedo-Litovitz model belong to this category. The other, to which the Adam-Gibbs and the Simmons-Macedo model belong, explicitly considers the cooperative motion of surroundings of flow units for viscous flow to occur.
Since silicate melts have been shown to be mixtures of silicate anions of varying size some of which are not spherical, applicability of the models in the former category are limited in principle only to a highly basic composition at which spherical anions, mostly $\mathrm{SiO}_{4}^{4-}$, are abundant. For silicate melts other than this composition, it becomes difficult to conceive a specific anion to be a flow unit, and hence parameters involved in viscosity expressions of the models in the former category lose their original significance. In this context, the models in the latter category are more comprehensive to cover wide variety of compositions. The Adam-Gibbs theory, however, is not yet satisfactory in view of the fact that experimental determination of $S_{c}$ is a tedious work and also the significance of $S_{c}$ is obscure particulary at temperatures much higher than $T_{g}$. Also, Simmons-Macedo model is insufficient because no explicit expression in terms of the microstructure is as yet worked out for total viscosity.

Local fluctuation of liquid structure leads to presuming the distribution with respect to a certain parameter $s$ of relaxation process involved in viscous flow. If the relaxation is regarded as a thermally activated process, then mean transition probability, $W(T)$, can be expressed by

$$
W(T)=\int_{s} a(s) \cdot f(s) \cdot \exp (-E(s) / R T) d s \ldots \ldots
$$

where, $a(s)$ is a factor to correlate the relaxation process to viscosity, $f(s)$ is the distribution function, and $E(s)$ is the activation energy. In the Macedo-Litovitz hybrid theory, which includes an Arrhenius type and a free volume type expression, $s, a(s)$, and $E(s)$ correspond to the free volume $v$, jump distance, and $E_{v}^{*}$, respectively, but dependence of $E_{v}^{*}$ on $v$ is neglected. In the Adam-Gibbs cooperative motion theory, $s$ and $E(s)$ correspond to $z$ and $z \Delta \mu$, respectively. Temperature dependence of $a(s)$ is included via that of $z^{*}$, the cut off number of segments. In this theory, however, a term, $f(s)$, is missing. In the SimmonsMacedo environmental relaxation model, $s$ is equivalent to the local liquid structure within a radius $r_{0}$. Unfortunately, however, no formulation of $a(s), f(s)$, and $E(s)$ is given explicitly.

Hard sphere version of non-equilibrium statiscomechanical description of viscosity falls within the same criticism as given to the modelistic theories in the former category. Namely, the version is applicable in its nature only to a melt of high basicity at which one may assume that the relaxation time for rotational motion is much shorter than translational one of flow units to which tentative mean radius may be assigned. Extention of nonequilibrium statiscomechanical approach to acid rich region seems to be impracticable, if not totally impossible.

Possibility of occurrence of viscosity anomaly as a result of cluster formation was recently discussed by Ikeda, Tamura, Shiraishi, and Saito ${ }^{74)}$ for $\mathrm{FeO}-\mathrm{SiO}_{2}$ melts. Influence of short range ordering on viscosity 
together with the mechanism of viscous flow of melts with acidic composition offer challenging topics to be explored in the near future.

\section{REFERENCES}

1) T. Emi: The Slag-Metal Reactions from Electrochemical Viewpoint, to be published in "Electrochemistry", ed. J.O'M. Bockris, Butterworths, London, (1975). Y. Kawai and K. Mori: Trans. ISIJ, 13 (1973), 303.

2) T. Emi, H. Nakato, K. Suzuki, Y. Iida, and T. Ueda: Tetsu-to-Hagané, 60 (1974), 981.

3) W. H. Zachariasen: J. Amer. Chem. Soc., 54 (1964), 3842.

4) B. E. Warren: J. Amer. Chem. Soc., 19 (1936), 202.

5) J. O'M. Bockris, J. A. Kitchener, S. Ignatowicz, and J. W. Tomlinson: Trans. Faraday Soc., 48 (1952), 75.

6) J. O'M. Bockris, J. W. Tomlinson, and J. L. White: Trans. Faraday Soc., 52 (1956), 299.

7) J. W. Tomlinson, M. S. R. Heynes, and J. O'M. Bockris: Trans. Faraday Soc., 54 (1958), 1822.

8) M. Temkin: Zur. Fiz. Khim, 20 (1946), 105.

9) G. W. Toop and C. S. Samis: Trans. Met. Soc. AIME, 224 (1962), 878.

10) M. L. Kapoor and M. Frohberg: Arch. Eisenhüttenw., 41 (1970), 1035

11) T. Yokokawa and K. Niwa: Trans. JIM, 10 (1969), 3.

12) C. R. Masson: Proc. Roy. Soc., A287 (1965), 201.

13) C. R. Masson: J. Amer. Ceram. Soc., 51 (1968), 134.

14) S. G. Whiteway, I. B. Smith, and C. R. Masson: Can. J. Chem., 48 (1970), 34, 202, 1456; I. B. Smith and C. R. Masson: Can. J. Chem., 49 (1971), 684.

15) C. R. Masson: JISI, 11 (1972), 89.

16) D. R. Gaskell: Met. Trans., 4 (1973), 185.

17) T. Yokokawa: Bull. Japan Inst. Met., 13 (1974), 3.

18) B. Pretnar: Ber. Busengesell. Phys, Chem., 72 (1968), 773.

19) C. F. Baes, Jr.: J. Solid State Chem., 1 (1970), 159.

20) T. Yanagase and Y. Suginohara: Trans. JIM, 11 (1970), 400 .

21) C. W. Lentz: Inorg. Chem., 3 (1964), 574.

22) J. Götz and C. R. Masson: J. Chem. Soc., A (1970), 2683.

23) J. Götz and C. R. Masson: J. Chem. Soc., A (1971), 686.

24) I. B. Smith and C. R. Masson: Can. J. Chem., 49 (1971), 683.

25) S. Takeuchi and K. Furukawa: Phys. Chem. Process Metall., Interscience, New York, (1961), 245.

26) H. Flood and K. Hagemark: Acta Chem. Scand., 15 (1961), 1624.

27) T. Bates: Mod. Aspects of the Vitreous State, Ch. 5, 2, Butterworths, London, (1962).

28) C. R. Kurkjian and E. A. Sigety: Phys. Chem. Glasses, 9 (1968), 73.

29) T. Ito and K. Goto: Tetsu-to-Hagané, 60 (1974), 184.

30) G. H. Frischat: Glastech. Ber., 42 (1969), 182.

31) G. H. Frischat and G. Tomandl: Glastech. Ber., 44 (1971), 173.

32) L. Pargamin: Ph. D. Thesis, Carnegie-Mellon Univ., (1971).

33) C. H. P. Lupis: Met. Trans., 3 (1972), 2093.

34) D. E. Day and G. E. Rindone: J. Amer. Ceram. Soc., 45 (1962), 489

35) Y. Suginohara and T. Yanagase: J. JIM, 31 (1967), 1229.

36) Y. Suginohara and T. Yanagase: J. JIM, 33 (1969), 290, 443.

37) D. Kumar, R. G. Ward and D. J. Williams: Discuss. Faraday Soc., 32 (1961), 147.

38) A. Mitchell: Trans. Faraday Soc., 63 (1967), 1408.
39) R. Sato: Bull. Japan Inst. Metals, 12 (1973), 391.

40) Y. Matsumura and Y. Shiraishi: Handbook of the Physical Properties of Molten Iron and Slags, Ch. 2, 54, ed. T. Saito (Iron and Steel Inst. Japan), (1972).

41) H. Ito and T. Yanagase: Trans. JIM, 1 (1960), 116.

42) S. Glasstone, K. J. Laidler, and H. Eyring: The Theory of Rate Processes, McGraw-Hill, New York, (1941).

43) T. Emi and J. O'M. Bockris: J. Phys. Chem., 74 (1970), 154.

44) A. Napolitano and E. G. Howkins: J. Res. Natl. Bur. Std., 68A (1964), 439.

45) D. B. Davies and A. J. Matheson: J. Chem. Phys., 45 (1966), 1000.

46) G. S. Fulcher: J. Amer. Ceram. Soc., 8 (1925), 339.

47) G. Tammann and W. Hesse: Z. anorg. allgem. Chem., 156 (1926), 245.

48) M. L. Williams, R. F. Landel, and J. D. Ferry: J. Am. Chem. Soc., 77 (1955), 3701.

49) O. G. Lewis: J. Chem. Phys., 43 (1965), 2693.

50) A. J. Barlow, J. Lamb, A. J. Matheson: Proc. Roy. Soc., A292 (1966), 322

A. J. Barlow, J. Lamb, A. J. Matheson, P. R. K. L. Padmini, and J. Richter: Proc. Roy. Soc., A298 (1967), 467.

A. J. Barlow, A. Erginsav, and J. Lamb: Proc. Roy. Soc. A298 (1967), 481.

51) S. A. Rice and P. Gray: The Statistical Mechanics of Simple Liquids, Intersci. Pub., New York, (1965).

52) M. Shimoji: Adv. Phys., 16 (1967), 705.

53) J. O'M. Bockris and D. L. Lowe: Proc. Roy. Soc., 226A (1954), 423.

54) J. O'M. Bockris and J. D. Mackenzie, and J. A. Kitchener: Trans. Faraday Soc., 51 (1955), 1734.

55) R. Powell, W. Roseveare and H. Eyring: Ind. Eng. Chem., 33 (1941), 430.

56) A. K. Doolittle: J. Appl. Phys., 22 (1951), 1471; 23 (1952), 231.

57) M. H. Cohen and D. Turnbull: J. Chem. Phys., 31 (1959), 1164.

58) M. H. Cohen and D. Turnbull: Nature, 203 (1964), 964.

$59)$ C. A. Angell: J. Amer. Ceram. Soc., 51 (1968), 117.

60) M. Sugisaki, H. Suga, and S. Seki: Bull. Chem. Soc. Japan, 41 (1968), 2591

61) O. Haida, H. Suga, and S. Seki: Thermochimica Acta, 3 (1972), 177.

62) O. Haida: Doctoral Thesis, Osaka Univ., (1973).

63) S. Kumar: Phys. Chem. Glasses, 4 (1963), 106.

64) P. B. Macedo and T. A. Litovitz: J. Chem. Phys., 42 (1965), 245.

65) H. S. Chung: J. Chem. Phys. 44 (1966), 1362.

66) P. B. Macedo and A. Napolitano: J. Chem. Phys., 49 (1968), 1887.

67) G. Adam and J. H. Gibbs: J. Chem. Phys., 43 (1965), 139.

68) J. Tauke, T. A. Litovitz, and P. B. Macedo: J. Amer. Ceram. Soc., 51 (1968), 158.

69) J. H. Simons and P. B. Macedo: J. Chem. Phys., 54 (1971), 1325; J. Res. Natl. Bur. Std., 75A (1971), 175.

70) J. H. Simons, A. Mills, and A. Napolitano: J. Non-Cryst. Solids, 14 (1974), 302.

71) S. A. Rice and J. G. Kirkwood: J. Chem. Phys., 31 (1959), 901.

72) T. Nozaki and M. Shimoji: Trans. Faraday Soc., 65 (1969), 1489.

73) A. Ejima and M. Shimoji: Trans. Faraday Soc., 66 (1970), 99.

74) K. Ikeda, A. Tamura, Y. Shiraishi, and K. Saito: Bull. Res. Inst. Min. Dress. Met. Tohoku Univ., 29 (1973), 24. 